\title{
EFFECT OF REPETITIVE TRANSCRANIAL MAGNETIC STIMULATION WITH HIGH FREQUENCY VERSUS LOW FREQUENCY ON MOTOR SYMPTOMS OF PARKINSON'S DISEASE
}

\author{
By \\ Kamel Mahmoud Hewedi, Ahmed Essmat Ali, and Ahmed Abdelbaset \\ Ahmed \\ Department of Neurology, AL-Azhar Faculty of Medicine, Cairo, Egypt \\ *Corresponding Author: Ahmed Abdelbaset Ahmed, Mobile: (+20) 01066995631 \\ E-Mail: a7medhamour@outlook.com
}

\begin{abstract}
Background: There is evidence that both high and low frequency repetitive transcranial magnetic stimulation (rTMS) may have therapeutic effects on motor performance of Parkinson's disease (PD).

Objective: The aim of the study was to conduct direct comparison of the two approaches.

Patients and Methods: Sixty PD patients who attended The Neurology Clinic of Kobri El-Koba Military Hospital, Maadi Military Hospital and Al-Hussien University Hospital, Egypt from December 2018 to October 2019. They were randomly classified into three groups. Group I (sham group) received inactive stimulation, Group II received $5 \mathrm{~Hz}$ and group III received $1 \mathrm{~Hz}$ rTMS with a total of 2000 pulses over primary motor cortex (M1) of each hemisphere for ten days. Effects were assessed with the Unified Parkinson's Disease Rating Scale part III (UPDRS) the day before stimulation, one week after the last session, and one month later.
\end{abstract}

Results: There was a significant improvement in all parts of UPDRS part III after $5 \mathrm{~Hz}$ rTMS (group II), and the effect persisted for one month after stimulation. As regard the Stage of disease, according to modified Hoehn and Yahr staging, there was an improvement in group II staging as nine patients improved to stage 2 where balance was regained and three patients in stage 5, as the severest stage, where patients were chair bound or bedridden improved partially to stage 4 and became able to walk unassisted with difficulty.

Conclusion: $5 \mathrm{~Hz}$ rTMS over M1 is superior to $1 \mathrm{~Hz}$ rTMS for motor symptoms of PD, particularly in advanced stages showing motor complication.

Keywords: Repetitive transcranial magnetic stimulation, parkinson's disease.

\section{INTRODUCTION}

Parkinson's disease (PD) is a progressive, debilitating neurodegenerative disease that affects dopaminergic neurotransmission, thereby resulting in motor symptoms e.g. resting tremor, bradykinesia, rigidity, gait disorder, and postural instability and non- motor symptoms, e.g. depression, dementia and sleep disorders (Yokoe et al., 2018).

$\mathrm{PD}$ is the second-most common neurodegenerative disorder that affects $2-$ $3 \%$ of the population $\geq 65$ years of age. Neuronal loss in the substantia nigra, which causes striatal dopamine 
deficiency, and intracellular inclusions containing aggregates of $\alpha$-synuclein are the neuropathological hallmarks of PD (Poewe et al., 2017).

The progressive loss of dopaminergic neurons in PD results in functional disruption within the cortico-basal ganglia-thalamo-cortical motor circuit. In particular, there is an excessive inhibition of thalamocortical projection to various cortical targets, including the primary motor cortex (M1), supplementary motor cortex (SMA) and dorsolateral prefrontal cortex (DLPFC). In addition, neurophysiological studies indicate altered corticospinal excitability. These functional changes in cortical activity are correlated with the cardinal motor symptoms in PD, including bradykinesia and rigidity (Chung et al., 2016).

Medical therapy substantially improves quality of life and functional capacity in PD. However, most patients develop complications after 5 years of treatment, including dyskinesia and motor fluctuations. Surgical techniques, including deep brain stimulation, improve advanced symptoms above the best medical therapy, although less than $5 \%$ of the PD population may be eligible for the procedure, (Chou et al., 2015).

Transcranial magnetic stimulation (TMS) is a method of non-invasive neurostimulatory and neuromodulatory technique increasingly utilized in clinics and research laboratories around the world it can transiently or lastingly modulate cortical excitability either increasing it or decreasing it by application of localized time varying magnetic field pulses (Horvath et al., 2013).
Repetitive TMS (rTMS) refers to regular repeated stimuli by single pulse TMS delivered in trains. Cortical excitability can be enhanced by highfrequency rTMS, whereas low frequency rTMS induces the depression of cortical activity. In addition to the local stimulatory effect on the cortical area, rTMS can also induce a distant effect on other cortical and subcortical brain regions probably via the cortico-basal ganglia-thalamo-cortical motor circuits. Therefore, rTMS applied to various cortical areas has been used to treat motor dysfunction in PD (Chung et al., 2016).

Usually, rTMS induces synaptic plasticity in the cortical area underneath a magnetic coil. In PD treatments, a long term potentiation (LTP) was induced in the primary or supplementary motor cortex (M1 or SMA) whose excitability is supposed to be depressed in PD (Matsumoto et al, 2017).

TMS is approved for the treatment of major depressive disorder (MDD), and there is a substantial body of evidence to suggest that TMS may also be effective in treating a variety of other neurological and psychiatric disorders including Parkinson's disease, and motorrehabilitation post-stroke, schizophrenia, anxiety disorders (Sathappan et al., 2019).

The present work aimed to conduct direct comparison of the two approaches by comparing simply the effect of "standard" versions of high and low frequency rTMS with a control group (sham group) on motor outcome of PD.

\section{PATIENTS AND METHODS}

Seventy-two consecutive patients (46 males and 26 females) who fulfilled the 
UK Parkinson's Disease Brain Bank criteria for idiopathic PD (Kačar et al., 2017), with ages between 58-79 years were recruited from those who attended the neurology clinic of Kobri El-Koba Military Hospital, Maadi Military Hospital and Al-Hussien University Hospital, Egypt, from December 2018 to October 2019. Patients were divided into three groups, Control group (Group I), High frequency group (group II), and Low frequency group (group III).

Out of 72 patients, 12 patients were excluded because 3 patients had a history of seizures, 2 patients had a history of cerebrovascular stroke, and 3 patients had a pacemaker and 4 patients with history of anti-psychotic drugs. The remaining 60 patients participated in the clinical trial. All patients were receiving medication that was maintained constant for the duration of the trial. All participants or their caregivers gave informed consents before participation in the test and after full explanation of the study protocol. The local ethical committee of Al-Azher University Hospital approved the study protocol.

All evaluations were performed by a clinician who was unaware of the treatment group. According to the unified Parkinson disease rating scale (UPDRS) patients were assessed clinically with the motor part III and part IV for complications of therapy. In addition, Hoehn and Yahr scale was used for clinical staging. UPDRS is the best scale for clinical evaluation of PD (Zanjani et al., 2015). These were performed using rTMS. Khedr et al., (2014) we measured resting (RMT) and active (aMT) motor threshold, MEP (motor evoked potential) amplitude at $130 \%$ rMT of the first dorsal interosseous muscle (FDI) using single TMS pulses with the coil held so as to induce currents approximately perpendicular to the line of the central sulcus.

The patients were divided into three groups, Group I (Control group), Group II (High frequency group), and Group III (Low frequency group).

Group I patients (sham group) were blindly subjected to inactive stimulation (sham stimulation) without knowing the difference between active and inactive stimulation. The position of the coil was identical to that of the active coil. The look and the feeling of the sham stimulation will be very similar but not identical to the active stimulation. They incorrectly picked the sham as an active stimulation.

Group II (High frequency group) patients received 2000 pulses of $5 \mathrm{~Hz}$ rTMS (delivered in trains of 100 pulses for each train with $20 \mathrm{~s}$ between trains) over M1 at $90 \%$ of RMT for each hemisphere ( $5 \mathrm{~min}$ between hemispheres).

\section{Group III patients (Low frequency} group) received bilateral stimulation at 1 $\mathrm{Hz}$ rTMS (each hemisphere received two trains, separated by $30 \mathrm{~s}$, of 1000 stimuli at $100 \%$ RMT).

During rTMS all patients were wearing ear plugs to protect the ears from the acoustic artifact associated with the discharge of the stimulation coil. 10 sessions were received once per day for 10 consecutive days for each patient. None of the patients had rTMS before or aware of the importance of differences in stimulation frequency and site. 
We followed up the patients clinically one week after the end of the $10^{\text {th }}$ session and one month later using the same clinical rating scale.

\section{Statistical analysis:}

Data were collected, revised and entered to the statistical package for social science (SPSS) version 20. The results were expressed as Means, standard deviations (SD), numbers and percentages. The comparison between three groups regarding qualitative data were done by using Chi-square test while for quantitative data with parametric distribution were done by using One Way ANOVA and for non-parametric distribution were done by using KruskallWallis test. The comparison between data at more than two times of measurement was done by using Friedman test when the data were with non-parametric distribution and Repeated Measures ANOVA with parametric distribution data. The confidence interval was set to $95 \%$ and the margin of error accepted was set to $5 \%$. So, the p-value was considered significant at the level of $<0.05$.

\section{RESULTS}

There were no significant differences between groups as regards age, sex, duration of illness, stage of the disease, and total score of UPDRS III. Patients were assessed clinically on medication at baseline (the day before the first rTMS session), one week after the last session, and then one month later (Table 1).

Table (1): Demographic data at baseline assessment

\begin{tabular}{|c|c|c|c|c|c|}
\hline \multirow{2}{*}{\multicolumn{2}{|c|}{ Before rTMS stimulation }} & Group I & Group II & Group III & \multirow{2}{*}{ P-value } \\
\hline & & No. $=20$ & No. $=20$ & No. $=20$ & \\
\hline \multirow{2}{*}{ Age } & Mean \pm SD & $66.65 \pm 5.73$ & $66.45 \pm 4.57$ & $68.05 \pm 4.30$ & \multirow{2}{*}{$0.536^{\circ}$} \\
\hline & Range & $58-79$ & $58-74$ & $59-75$ & \\
\hline \multirow{2}{*}{ Sex } & Female & $8(40.0 \%)$ & $9(45.0 \%)$ & $9(45.0 \%)$ & \multirow{2}{*}{$0.934^{*}$} \\
\hline & Male & $12(60.0 \%)$ & $11(55.0 \%)$ & $11(55.0 \%)$ & \\
\hline Duration of illness in months & $\begin{array}{c}\text { Mean } \pm \text { SD } \\
\text { Range }\end{array}$ & $\begin{array}{c}68.60 \pm 5.30 \\
60-80\end{array}$ & $\begin{array}{c}68.35 \pm 4.76 \\
60-80\end{array}$ & $\begin{array}{c}68.95 \pm 4.57 \\
62-79\end{array}$ & $0.927^{\bullet}$ \\
\hline $\begin{array}{c}\text { Stage of disease } \\
\text { according to } \\
\text { modified Hoehn and } \\
\text { Yahr staging }\end{array}$ & $\begin{array}{c}\text { Mean } \pm \text { SD } \\
\text { Range }\end{array}$ & $\begin{array}{c}3.70 \pm 0.73 \\
3-5\end{array}$ & $\begin{array}{c}3.80 \pm 0.70 \\
3-5\end{array}$ & $\begin{array}{c}3.75 \pm 0.72 \\
3-5\end{array}$ & $0.881^{\#}$ \\
\hline UPDRS part III (motor part) & $\begin{array}{l}\text { Mean } \pm \text { SD } \\
\text { Range }\end{array}$ & $\begin{array}{c}46.65 \pm 6.12 \\
38-56\end{array}$ & $\begin{array}{c}45.55 \pm 5.91 \\
37-56\end{array}$ & $\begin{array}{c}46.70 \pm 6.06 \\
36-55\end{array}$ & $0.793^{\circ}$ \\
\hline
\end{tabular}

•: One Way ANOVA; *: Chi-square test; \#: Kruskall-Wallis test

We used the UPDRS motor part III for clinical evaluation and follow up in our patients. In group II (High frequency group) there was a significant improvement regarding the total score of UPDRS part III one week after stimulation that lasted one month later. On the other hand, group I (sham stimulation) and group III (low frequency group) didn't show any significant effect (Table 2).

As regard the stage of disease, at the end of the study, according to modified Hoehn and Yahr staging there was improvement in group II staging as nine 
patients improved to stage 2, where balance was regained (no patients fulfilled these criteria at the start of the study) and three patients in stage 5, as the severest stage, where patients were chair bound or bedridden improved partially to stage 4 and became able to walk unassisted with difficulty. On the other hand, group I (sham stimulation) and group III (low frequency group) didn't show any change in the stage of the disease (Table 2).

Table (2): showing significance improvement in group II patients one week after rTMS that lasted one month after rTMS stimulation and no significance effect in group I and group III as regard as stage of the disease and total UPDRS part III

\begin{tabular}{|c|c|c|c|c|c|c|}
\hline \multirow[t]{2}{*}{ Measure } & \multirow{2}{*}{\multicolumn{2}{|c|}{$\begin{array}{c}\text { Group } \\
\text { (number of patients) }\end{array}$}} & Before rTMS & 1 Week after rTMS & $\begin{array}{c}\text { Month after } \\
\text { rTMS }\end{array}$ & \multirow[t]{2}{*}{ P-value } \\
\hline & & & No. $=20$ & No. $=20$ & No. $=20$ & \\
\hline \multirow{3}{*}{$\begin{array}{l}\text { Stage of disease } \\
\text { according to } \\
\text { modified Hoehn } \\
\text { and Yahr staging }\end{array}$} & Group I & $\begin{array}{l}\text { Mean } \pm \text { SD } \\
\text { Range }\end{array}$ & $\begin{array}{c}3.70 \pm 0.73 \\
3-5\end{array}$ & $\begin{array}{c}3.70 \pm 0.73 \\
3-5\end{array}$ & $\begin{array}{c}3.70 \pm 0.73 \\
3-5\end{array}$ & $1.000^{\#}$ \\
\hline & Group II & $\begin{array}{l}\text { Mean } \pm \text { SD } \\
\text { Range }\end{array}$ & $\begin{array}{l}3.80 \pm 0.70 \\
3-5\end{array}$ & $\begin{array}{c}2.90 \pm 1.02 \\
2-5\end{array}$ & $\begin{array}{c}2.90 \pm 1.02 \\
2-5\end{array}$ & $0.000^{\#}$ \\
\hline & Group III & $\begin{array}{l}\text { Mean } \pm \text { SD } \\
\text { Range }\end{array}$ & $\begin{array}{c}3.75 \pm 0.72 \\
3-5\end{array}$ & $\begin{array}{c}3.70 \pm 0.80 \\
2-5\end{array}$ & $\begin{array}{c}3.70 \pm 0.80 \\
2-5\end{array}$ & $0.368^{\#}$ \\
\hline \multirow{3}{*}{$\begin{array}{l}\text { UPDRS part III } \\
\text { (motor part) }\end{array}$} & Group I & $\begin{array}{l}\text { Mean } \pm \text { SD } \\
\text { Range }\end{array}$ & $\begin{array}{c}46.65 \pm 6.12 \\
38-56\end{array}$ & $\begin{array}{c}46.55 \pm 5.87 \\
38-56\end{array}$ & $\begin{array}{c}46.75 \pm 5.99 \\
38-56\end{array}$ & $0.619 \bullet$ \\
\hline & Group II & $\begin{array}{l}\text { Mean } \pm \text { SD } \\
\text { Range }\end{array}$ & $\begin{array}{c}45.55 \pm 5.91 \\
37-56\end{array}$ & $\begin{array}{c}33.70 \pm 9.69 \\
24-55\end{array}$ & $\begin{array}{c}33.95 \pm 9.19 \\
24-54\end{array}$ & $0.000 \bullet$ \\
\hline & Group III & $\begin{array}{l}\text { Mean } \pm \text { SD } \\
\text { Range }\end{array}$ & $\begin{array}{c}46.70 \pm 6.06 \\
36-55\end{array}$ & $\begin{array}{c}46.55 \pm 6.17 \\
36-56\end{array}$ & $\begin{array}{c}46.35 \pm 6.09 \\
36-56\end{array}$ & $0.673 \bullet$ \\
\hline
\end{tabular}

•: Repeated Measures ANOVA; \#: Freidman test

In Group II, besides, improving the total score of UPDRS part III we noted significant improvement in all items of
UPDRS part III after the end of stimulation that lasted one month later (Figure 1).

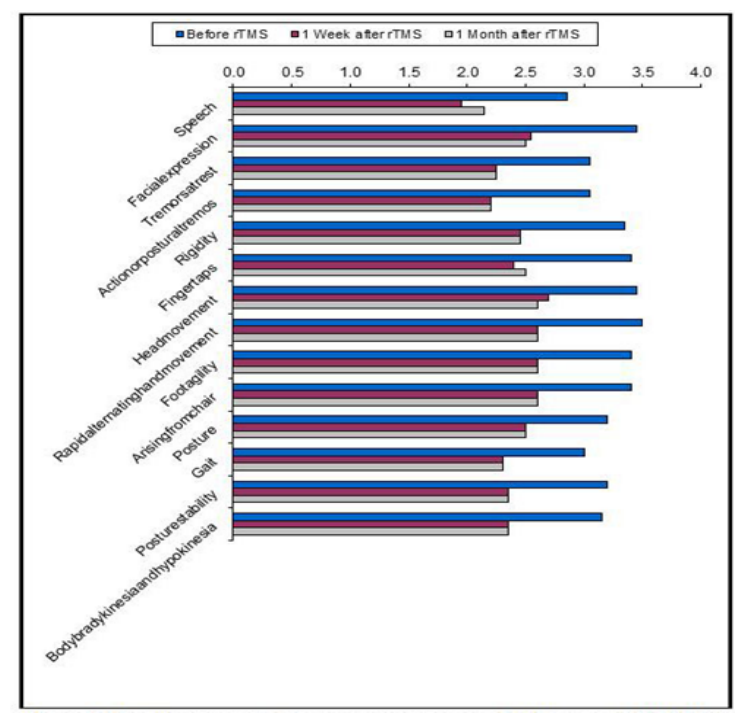

Figure (1): Showing significance improvement of all items of UPDRS part III in group II patients one month after rTMS that lasted one month after rTMS stimulation UPDRS 
Regarding effect of rTMS on complications of therapy, in group II (High frequency group), we found a significant improvement in Dyskinesias, Clinical Fluctuations, anorexia, nausea and vomiting) one week after stimulation that lasted one month later after rTMS. however, we didn't found a significant effect as regard as sleep disturbances and orthostatic hypotension as. On the other hand, group I (sham stimulation) and group III (low frequency group) didn't show any significant effect (Table 3).

Table (3): Showing significance improvement in group II patients one week after rTMS that lasted one month after rTMS stimulation as regard complications of therapy

\begin{tabular}{|c|c|c|c|c|c|}
\hline \multirow{2}{*}{\multicolumn{2}{|c|}{ Group II }} & Before rTMS & $\begin{array}{c}1 \text { Week } \\
\text { after rTMS }\end{array}$ & $\begin{array}{c}1 \text { Month } \\
\text { after rTMS }\end{array}$ & \multirow[t]{2}{*}{$\begin{array}{c}\text { P- } \\
\text { value }^{\#}\end{array}$} \\
\hline & & No. $=20$ & No. $=\mathbf{2 0}$ & No. $=20$ & \\
\hline \multirow{2}{*}{ Dyskinesia duration } & Mean \pm SD & $0.95 \pm 1.10$ & $0.45 \pm 0.89$ & $0.45 \pm 0.89$ & \multirow{2}{*}{0.000} \\
\hline & Range & $0-3$ & $0-3$ & $0-3$ & \\
\hline \multirow{2}{*}{ Dyskinesia disability } & Mean \pm SD & $1.00 \pm 1.17$ & $0.55 \pm 1.05$ & $0.55 \pm 1.05$ & \multirow{2}{*}{0.000} \\
\hline & Range & $0-4$ & $0-4$ & $0-4$ & \\
\hline \multirow{2}{*}{ Painful Dyskinesia } & Mean \pm SD & $0.98 \pm 1.13$ & $0.44 \pm 0.88$ & $0.44 \pm 0.89$ & \multirow{2}{*}{0.002} \\
\hline & Range & $0-3$ & $0-3$ & $0-3$ & \\
\hline \multirow{2}{*}{ Dyskinesia morning dystonia } & M ean \pm SD & $0.65 \pm 0.49$ & $0.25 \pm 0.44$ & $0.25 \pm 0.44$ & \multirow{2}{*}{0.031} \\
\hline & Range & $0-1$ & $0-1$ & $0-1$ & \\
\hline \multirow{2}{*}{ Clinical fluctuations. Sudden offs } & Mean \pm SD & $0.50 \pm 0.51$ & $0.20 \pm 0.41$ & $0.20 \pm 0.41$ & \multirow{2}{*}{0.002} \\
\hline & Range & $0-1$ & $0-1$ & $0-1$ & \\
\hline \multirow{2}{*}{$\begin{array}{l}\text { Clinical fluctuations proportion of offs } \\
\text { to waking day }\end{array}$} & Mean \pm SD & $2.80 \pm 0.70$ & $2.00 \pm 0.92$ & $2.00 \pm 0.92$ & \multirow{2}{*}{0.000} \\
\hline & Range & $2-4$ & $1-4$ & $1-4$ & \\
\hline \multirow{2}{*}{ Anorexia, nausea, vomiting } & Mean \pm SD & $0.64 \pm 0.48$ & $0.24 \pm 0.43$ & $0.24 \pm 0.43$ & \multirow{2}{*}{0.000} \\
\hline & Range & $0-1$ & $0-1$ & $0-1$ & \\
\hline \multirow{2}{*}{ Sleep disturbance } & Mean \pm SD & $0.85 \pm 0.37$ & $0.60 \pm 0.50$ & $0.60 \pm 0.50$ & \multirow{2}{*}{0.103} \\
\hline & Range & $0-1$ & $0-1$ & $0-1$ & \\
\hline \multirow{2}{*}{ Symptomatic orthostasis } & Mean \pm SD & $0.45 \pm 0.51$ & $0.50 \pm 0.51$ & $0.50 \pm 0.51$ & \multirow{2}{*}{0.819} \\
\hline & Range & $0-1$ & $0-1$ & $0-1$ & \\
\hline
\end{tabular}

\#: Freidman test

\section{DISCUSSION}

Several rTMS studies have been conducted with the objective of improving motor symptoms in PD overall they provided mixed results. These studies differed with regard to rTMS protocols (high/low frequency), cortical areas stimulated (M1, prefrontal cortex), sample size, disease duration, and therapeutic aims (bradykinesia, handwriting, tremor, gait, etc.) (Latorre et al., 2019).

Because of the provided mixed results our clinical trial compares simply the effect of standard versions of high, low frequency rTMS and a control (sham group) on motor outcome of PD.
Chung and Mak (2016) carried out a systematic review and meta-analysis about the effect of rTMS on physical functions and motor signs in PD. Their aim was to examine the efficacy of rTMS. In improving physical function and motor signs over the short and long term in PD. This was measured by the motor section of UPDRS- section III. Their second subjective was to investigate whether rTMS parameters (intensity, frequency, stimulation site and total number of stimulation pulses) were associated with the effect size of rTMS on motor performance. The meta-analysis of the results showed that the effect size was 


\section{EFFECT OF REPETITIVE TRANSCRANIAL MAGNETIC STIMULATION ...}

statistically significant in favor of the intervention.

This coincides with the results of previous investigators in this field who found mild to moderate improvement in an interesting study Fregni et al. (2004) published a systematic review and metaanalysis of the literature to quantify the efficacy of rTMS on the treatment motor dysfunction in PD patients. Only 12 studies were found in the literature up to this date to fulfill the inclusion criteria for this study. They used the motor subscale of UPDRS. At the end of their study, they went to the conclusion that non-invasive brain stimulation (rTMS) can be effective in improving the motor symptoms of PD but the effect is modest.

Regarding the site of stimulation, we stimulated primary motor areas (M1) bilaterally. This site was stimulated by Maruo et al. (2013). Others stimulated supplementary motor area (SMA) (Shirota et al. 2013); still others stimulated dorsolateral prefrontal cortex (DIPFC) (Sedlakovas et al., 2009 and Nardone et al., 2013).

Chung and Mak (2016) also found that when stimulation site in M1 (primary motor area) the effect is better than stimulation of supplementary motor area (SMA) and dorsolateral prefrontal cortex (DLPFC). This coincides in our study that stimulated primary motor area (M1) bilaterally.

The long-term effect of rTMS on UPDRS III scores was reported in four parallel design trials (Pal et al., 2010; Benninger et al., 2011, 2012; and Shirota et al., 2013). Long-term effect on UPDRS III was evident after real rTMS, but with a moderate level of heterogeneity in the estimates.

Results of meta-regression showed that at short term, there was a larger affected size on UPDRS III scores. Among trials using rTMS over primary motor area M1 with greater number of stimulation pulses and with more rTMS sessions. The total number of stimulation pulses in these trials ranged from 600-20000 (mean $6251.4+-8586.4)$ delivered over 1-10 sessions. This also coincides with our study as we used rTMS for 10 days.

Regarding frequency our findings support the meta-analysis of the effects of HF-rTMS versus LF-rTMS recently conducted by (Lattore et al., 2019), that was consistent with the previous report of Elahi et al., (2009) who found a significant effect size of UPDRS-III for HF-rTMS studies but not significant for LF-rTMS studies and this coincides with our study.

Distinct results, however, were observed in some other meta-analysis studies in which no significant difference between HF-rTMS and LF-rTMS was found (Chou et al., 2015); an opposite result was discovered (Wagle et al., 2016) or no significant result was observed both in HF-rTMS and LF-rTMS (Chung and Mak, 2016).

The results of the present study are in contrast with the results of Mally et al. (2017). In their study, sixty-six patients with PD were included and randomly divided into three groups. The effects of 1 $\mathrm{Hz}, 5 \mathrm{~Hz}$ and $5+1 \mathrm{~Hz}$ frequency at low intensity over each DLPFC and the brain stem for 7 days were compared. Patients were followed for six months. They found that only $1 \mathrm{~Hz}$ had an effect on motor 
scores. Five Hertz and $5+1 \mathrm{~Hz}$ did not cause improvement. However, this was an open study trial and used a lower intensity of rTMS than in the present study ( $25 \%$ of maximum output. The reasons for these distinctions may be due to the differences in the included trials, data extraction, (Chou et al., 2015) and statistical methods (Wagle et al., 2016).

\section{CONCLUSION}

$5 \mathrm{~Hz}$ rTMS over M1 is superior to $1 \mathrm{~Hz}$ rTMS for motor symptoms of PD, particularly in advanced stages showing motor complication.

\section{RECOMMENDATIONS}

High frequency rTMS is superior to low frequency rTMS for therapeutic effect on motor symptoms of PD, however further studies are required to identify the optimal frequency, other stimulation parameters and the different patients' phenotypes and disease stages affect the response to rTMS for developing the best therapeutic strategy.

\section{REFERENCES}

1. Benninger, D., Berman, B., Houdayer, E., Pal, N., Luckenbaugh, D., Schneider, L., Miranda, S. and Hallett, M. (2011): Intermittent theta-burst transcranial magnetic stimulation for treatment of Parkinson disease. Neurology, 76: 601-609.

2. Benninger, D., Iseki, K., Kranick, S., Luckenbaugh, D., Houdayer, E. and Hallett, M. (2012): Controlled study of $50-\mathrm{Hz}$ repetitive transcranial magnetic stimulation for the treatment of parkinson disease. Neurorehabilitation and Neural Repair, 26: 1096-1105.

3. Chou, Y., Hickey, P., Sundman, M., Song, A., and Chen, N. (2015): Effects of repetitive transcranial magnetic stimulation on motor symptoms in parkinson disease: A systematic review and meta-analysis. JAMA Neurology, 72: 432-440.

4. Chung C., and Mak M. (2016): Effect of Repetitive Transcranial Magnetic Stimulation on Physical Function and Motor Signs in Parkinson's disease: A Systematic Review and Meta-Analysis Brain Stimulation, 9: 475-487.

5. Elahi, B., and Chen, R. (2009): Effect of transcranial magnetic stimulation on parkinson motor function - Systematic review of controlled clinical trials. Movement Disorders, 24:357-363.

6. Fregni, F., Santos, C., Myczkowski, M., Rigolino, R., Gallucci-Neto, J., Barbosa, E., Valente, K., Pascual-Leone, A., and Marcolin, M. (2004): Repetitive transcranial magnetic stimulation is as effective as fluoxetine in the treatment of depression in patients with Parkinson's disease. J Neur61 Neurosurg Psychiatry, 75 (8): 1171-1 174.

7. Horvath, J., Perez, J., Forrow, L., Fregni, F., and Pascual-Leone, A. (2013): Transcranial Magnetic Stimulation: Future Prospects and Ethical Concerns in Treatment and Research. In Neuroethics in Practice, (Oxford University Press), p.

8. Kačar, A., Milanović, S., Filipović, S., and Ljubisavljević, M. (2017): Changes in cortical excitability during paired associative stimulation in Parkinson's disease patients and healthy subjects. Neuroscience Research 124, 51-56.

9. Khedr E, Gamal N, El-Fetoh N, Khalifa H, Ahmed E, Ali A, Noaman M, El-Baki A, and Karim A. (2014): A double-blind randomized clinical trial on the efficacy of cortical direct current stimulation for the treatment of Alzheimer's disease. Front Aging Neurosci6, 275.

10. Latorre, A. Rocchi, A. Berardelli, K., and Bhatia, J. (2019): Rothwell, The use of transcranial magnetic stimulation as a treatment for movement disorders: A critical review. Movement Disorders, doi:10.1002/mds.27705. references

11. Mally J, Geisz N., and Dinya E. (2017): Follow up study: The influence of rTMS with high and low frequency stimulation on motor 
and executive function in Parkinson's disease. Brain Res Bull135, 98-104.

12. Maruo, T., Hosomi, K., Shimokawa, T., Kishima, H., Oshino, S., Morris, S., Kageyama, Y., Yokoe, M., Yoshimine, T., and Saitoh, Y. (2013): High-frequency repetitive transcranial magnetic stimulation over the primary foot motor area in Parkinson's disease. Brain Stimul, 6 (6): 884891.

13. Matsumoto, H., and Ugawa, Y. (2017): Repetitive transcranial magnetic stimulation for Parkinson's disease: A review. Brain and Nerve 69.

14. Nardone, R., De Blasi, P., Höller, Y., Christova, M., Tezzon, F., Trinka, E., and Brigo, F (2013): Repetitive transcranial magnetic stimulation transiently reduces punding in Parkinson's disease: a preliminary study. J Neural Transm, 121 (3): 267-74.

15. Pal E, Nagy F, Aschermann Z, Balazs E and Kovacs $N$ (2010): The impact of left prefrontal repetitive transcranial magnetic stimulation on depression in parkinson's disease: a randomized, double-blind, placebocontrolled study. Mov Disord, 25 (14): 231 12317.

16. Poewe, W., Seppi, K., Tanner, C., Halliday, G., Brundin, P., Volkmann, J., Schrage, A., and Lang, A. (2017): Parkinson disease. Nature Reviews Disease Primers, 3: 1-2.

17. Sathappan, A., Luber, B., and Lisanby, S. (2019): The dynamic Duo: Combining noninvasive brain stimulation with cognitive interventions. Progress in NeuroPsychopharmacology and Biological Psychiatry 89, 347-360.
18. Sedlackova S, Rektorova I, Srovnalova H and Rektor I (2009): Effect of high frequency repetitive transcranial magnetic stimulation on reaction time, clinical features and cognitive functions in patients with Parkinson's disease. J Neural Transm, 116 (9): 1093-1 101.

19. Shirota, Y., Ohtsu, H., Hamada, M., Enomoto, H., and Ugawa, Y. (2013): Supplementary motor area stimulation for Parkinson disease: A randomized controlled study. Neurology 80, 1400-1405.

20. Wagle Shukla, A., Shuster, J., Chung, J., Vaillancourt, D., Patten, C., Ostrem, J., and Okun, M. (2016): Repetitive Transcranial Magnetic Stimulation (rTMS) Therapy in Parkinson Disease: A Meta-Analysis. PM and R 8, 356-366.

21. Yokoe, M., Mano, T., Maruo, T., Hosomi, K., Shimokawa, T., Kishima, H., and Shimizu, T. (2018): The optimal stimulation site for high-frequency repetitive transcranial magnetic stimulation in Parkinson's disease: A double-blind crossover pilot study. Journal of Clinical Neuroscience, 47, 72-78.

22. Zanjani A, Zakzanis $K$, Daskalakis $Z$ and Chen $R$ (2015): Repetitive transcranial magnetic stimulation of the primary motor cortex in the treatment of motor signs in Parkinson's disease: a quantitative review of the literature. Mov Disord; 30 (6): 750-758. 
تأثير التحفيز المتكرر المغناطيسى عبر الدماغ ذو التردد العالى مقابل ذو التردد المنخفض علي الأعر اض الحفن الحركيه في مرض بار كنسون

كامل محمود هويدي، أحمد عصمت علي، أحمد عبدالباسط أحمد حمور قسم طب المخ و الأعصاب، كلية الطب، جامعة الأزهر، القاهرة

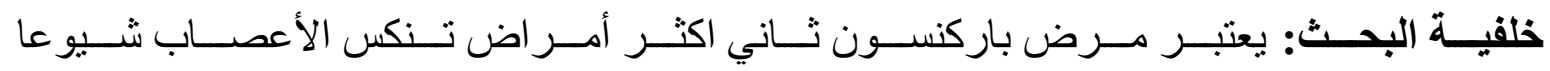

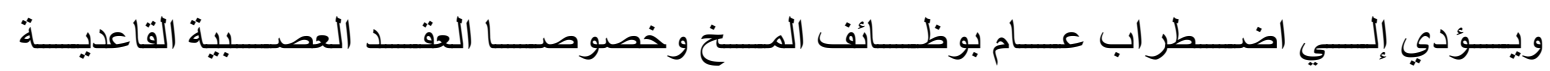

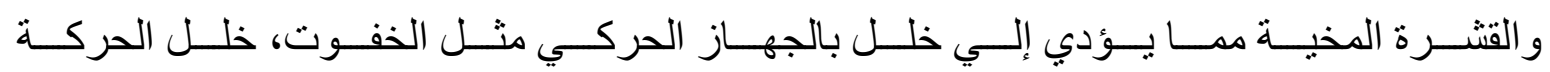

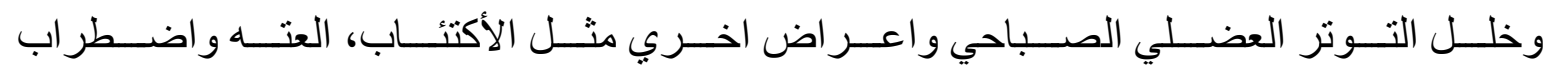

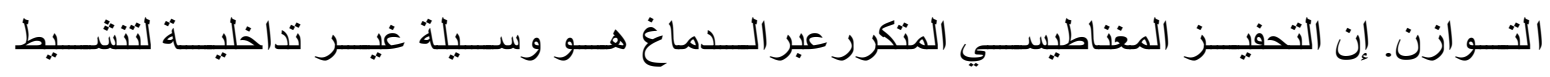

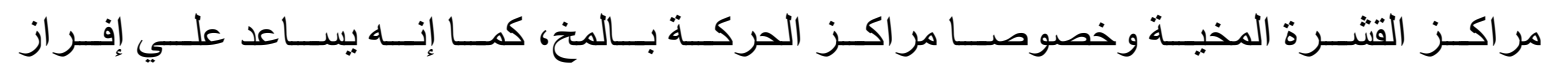

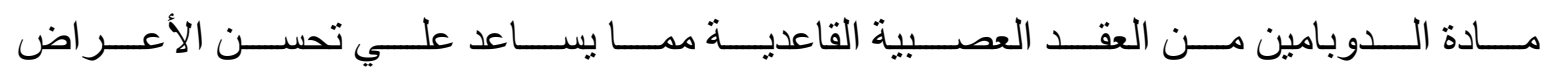
الحركية للمريض بالإضافة للأعر اض الأخري مثل الإكتئاب.

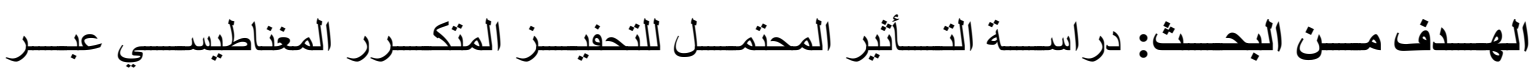

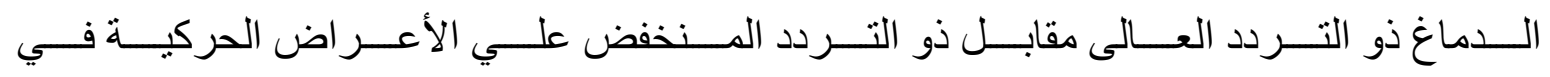
مرض باركنسون.

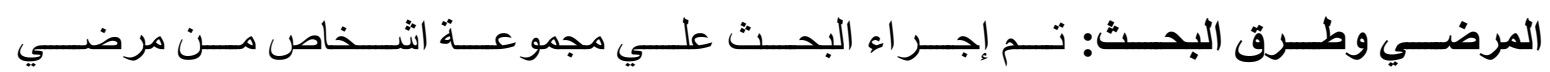

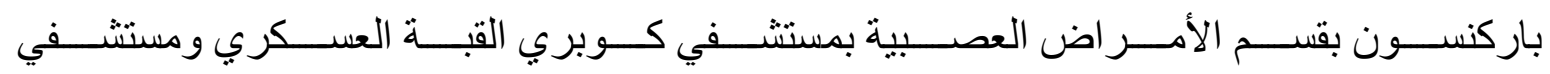
المعادي العسكري ومستشفي الحسين الجامعي.

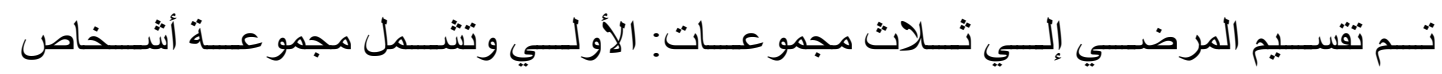

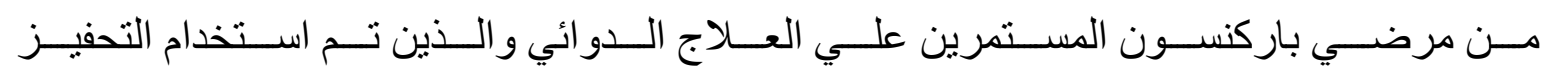

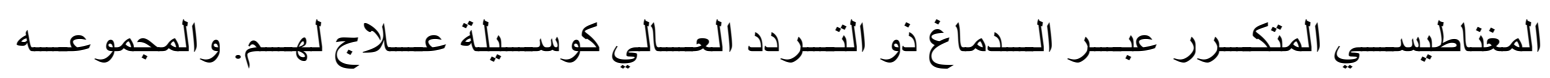

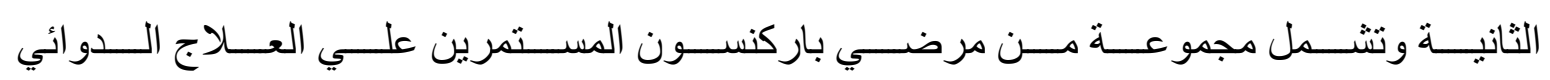

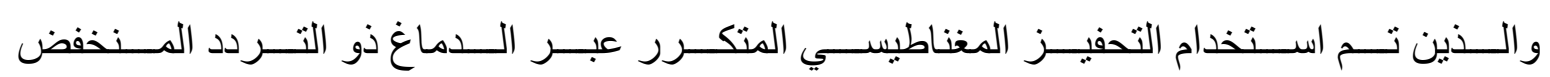

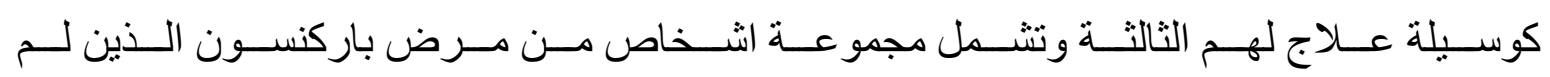

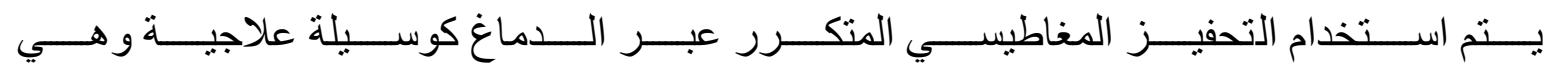


EFFECT OF REPETITIVE TRANSCRANIAL MAGNETIC STIMULATION ...

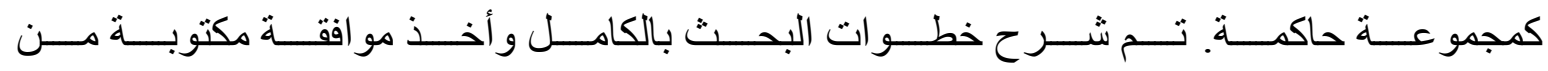

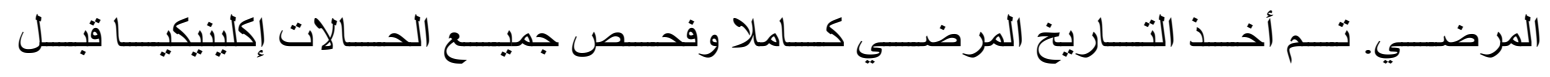

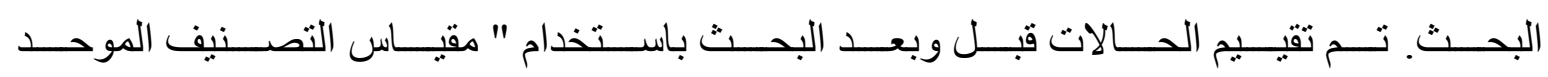

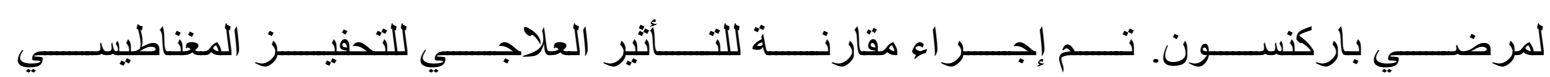
المتكرر عبر الدماغ بين المجموعات الثناث.

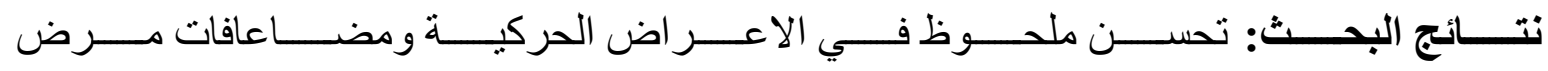

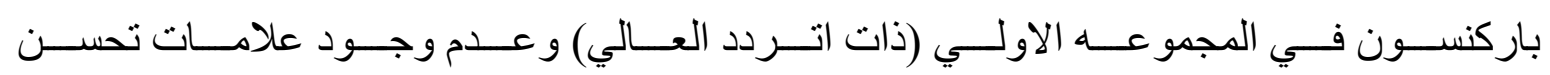
في المجمو عه الثانية (ذات التردد المنخفض) أو المجموعة الحاكمة.

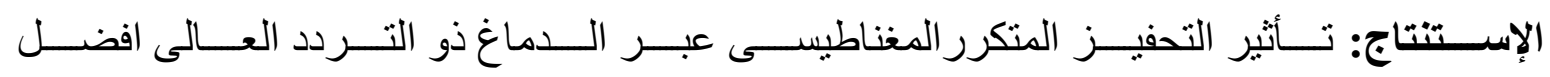

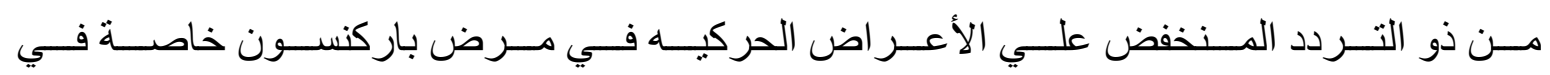
المر احل المتقدمة ذات المضاعفات. 